\title{
CONSERVATIVE SURGICAL MANAGEMENT OF UTEROVAGINAL PROLAPSE IN YOUNG WOMEN
}

\author{
Chetan Ashok Pawar1, Monali Prakash Deshmukh²
}

${ }^{1}$ Associate Professor, Department of Obstetrics and Gynaecology, Shri Bhausaheb Hire Government Medical College, Dhule, Maharashtra.

${ }^{2}$ Assistant Professor, Department of Obstetrics and Gynaecology, Shri Bhausaheb Hire Government Medical College, Dhule, Maharashtra.

\section{ABSTRACT}

\section{BACKGROUND}

Uterovaginal Prolapse implies failure of one or more of the supports of the uterus and vagina that prevents the abdominal and pelvic organs from falling through the opening within the bony pelvis. Various vaginal plastic or reparative operations have strongly resembled one another in order to restore the support of pelvic organs. So the present study aimed to evaluate various modalities of conservative surgical management and their outcome.

\section{MATERIALS AND METHODS}

The study comprises of 40 women in reproductive age group within 18 - 35 years with varying degrees of prolapse treated by conservative surgeries. Contraindication for surgery was the excluding criteria. Type of conservative surgeries, indications outcome and followup evaluation was done.

\section{RESULTS}

Majority of women, i.e. 75\% were of 21 to 30 years' age group. Past obstetric history of prolonged and difficult labour was in $20 \%$ and multi-parity in $77.5 \%$ women. Something coming out per-vagina was most common (100\%) complaint with low back pain Majority of women, i.e. $47.5 \%$ had 3 inches uterocervical length. Purandare's abdominal cervicopexy and Shirodkar's uterosacral advancement needed in $20 \%$ and $15 \%$ respectively, $30 \%$ had Shirodkar's sling surgery, $15 \%$ underwent Nadkarni's sleeve operation, Fothergill's operation and laparoscopic assisted cervicopexy was done in 10\% each. All sling operations were done for Grade III descents. Conception rate was $25 \%$ by Shirodkar's sling operation, $66.66 \%$ by Nadkarni's sleeve excision. No recurrence was noted after any procedure during study period.

\section{CONCLUSION}

Different procedures in conservative surgeries of uterovaginal prolapse have their own advantages and disadvantages. Patient with prolapse are not approached with fixed plans. Individual preference with surgical skills varies with the operating surgeons and experience.

\section{KEYWORDS}

Uterovaginal Prolapse, Supports of the Uterus and Vagina, Conservative Surgeries.

HOW TO CITE THIS ARTICLE: Pawar CA, Deshmukh MP. Conservative surgical management of uterovaginal prolapse in young women. J. Evolution Med. Dent. Sci. 2017;6(30):2462-2465, DOI: 10.14260/Jemds/2017/531

\section{BACKGROUND}

The occurrence of uterovaginal prolapse implies failure of one or more of the supports of the uterus and vagina. Activating factors to precipitate the onset of prolapse if a weakness is present are increased intra-abdominal pressure,[1] increasing parity, overweight are associated factors responsible for prolapse.

While vaginal prolapse can occur independently without uterine descent, the uterine prolapse is usually associated with variable degrees of vaginal descent.

The treatment of pelvic organ prolapse and its associated symptoms constitute a major subject in gynaecology.

Financial or Other, Competing Interest: None.

Submission 09-02-2017, Peer Review 30-03-2017,

Acceptance 05-04-2017, Published 13-04-2017.

Corresponding Author:

Dr. Chetan Ashok Pawar,

\#118, Yashodeep,

Jaihind Colony,

Deopur,

Dhule-424002.

E-mail: drchetanpawar@gmail.com

DOI: $10.14260 /$ jemds $/ 2017 / 531$

\section{(c) (i) $\$$}

Especially, in the advanced state the treatment of these conditions is one of the most challenging problems pelvic surgeons can face. Indeed, the success in treating prolapse is frequently used to judge skill of those surgeons.[2]

The pelvic floor lies at the base of the abdominal cavity and closes the canal within the bony pelvis, acts as supportive layer that prevents the abdominal and pelvic organs from falling through the opening within the bony pelvis. [3]

No condition has been used to judge the skill of gynaecological surgeon more than the ability to provide permanent relief of this classic malady with maintenance of restoration of normal functions.

The incidence of genital prolapse is difficult to determine as many women do not seek medical advice.[4] The annual incidence of hospital admission with a diagnosis of prolapse was $0.204 \%$, whereas the annual incidence of surgery for prolapse was $0.162 \% .{ }^{[5]}$

Pelvic organ prolapse is one of the most common indications for gynaecologic surgery. Prolapse has been reported as the most common reason for hysterectomy in women aged more than 50 years and accounts for $13 \%$ of hysterectomies in all age.[6] It is estimated that half of the women who have children will lose pelvic floor support and 
experience some degree of prolapse in later life and that of these women $10 \%$ - $20 \%$ seek medical care.[7]

Providing permanent relief by restoring normal anatomy and maximum physiologic function, always tests the ingenuity of gynaecologists. In spite of differences of opinion about which specific tissues in human pelvis are responsible for the support of pelvic organs, most vaginal plastic or reparative operations have strongly resembled one another.

Though pelvic organ prolapse is more common in elder women, it is now seen with an increased frequency even in reproductive age group. There is a noticeable and gradual shift towards minimally invasive procedures even for surgeries of prolapse.

Present study was planned with objective to study various aetiological factors associated with young age prolapse, modality of conservative surgical management and its outcome.

\section{MATERIALS AND METHODS}

This prospective observational study was conducted in Shri Bhausaheb Hire Government Medical College and General Hospital in Dhule within May 2013 to July 2016. The study comprises of analysis of 40 women of reproductive age group from 18 - 35 years with varying degrees of prolapse who were treated by conservative surgeries during the specified period. Study was approved by Institutional Ethical Committee.

These women wanted either preservation of their child bearing or menstrual function. Patients with morbid obesity, genital malignancies, adnexal or pelvic pathologies or suspicious Pap smear or D and C report, severe cardiorespiratory disease and thromboembolic disorders were excluded from the study.

A detailed history of symptoms comprised of duration, menstrual and obstetric history with special importance to previous difficult deliveries, history of vaginal instrumentations and previous surgeries.

Each patient underwent a thorough pelvic examination and degree of descent of uterus put forth by the International Continence Society[8] and uterocervical length and associated vaginal prolapse was noted. Patients were examined for tone of uterosacral ligaments, tone of perineal body and integrity of perineum.

Specific enquiry was made regarding presence or absence of SUI. Patients were posted for surgery postmenstrual. Patients who had decubitus ulcer were treated by a tampon dipped in glycerin acriflavine introduced daily till healing occurred, after which they were taken up for surgery.

Mostly patients were admitted one day prior to surgery and were counselled regarding the surgery and its complications. A detailed written, verbal and informed consent was taken. Patients were then given suitable anaesthesia and conservative surgeries were done according to the criteria, in which patient fitted. All patients were examined at the time of discharge. Patients were asked to follow-up in gynaecology outpatient department, every 3 monthly for 1 year and every 6 monthly thereafter. At every visit enquiry was made about recurrence of symptoms, urinary problems and about fertility.

Data was presented in frequency and percentage distribution.

\section{RESULTS}

Majority of 30 women (75\%) were in age group of 21 to 30 years. Eight patients (20\%) were more than 30 years. Only two patients were less than 20 years old.

$47.5 \%$ had history of rapid successive delivery, $20 \%$ had history of prolonged and difficult labour. No patients had history of instrumental deliveries. Maximum patients, i.e. $52.5 \%$ had two living children, $20 \%$ had only one living child while $27.5 \%$ had 3 and more living children; $2.5 \%$ women were nullipara, $20 \%$ were para 1 while $77.5 \%$ were having parity one and above.

One patient had history of abdominal Koch's and had completed her AKT course before surgery. Chest x-ray done was within normal limits and patient was taken up after declared fit for surgery.

All patients complained of something coming out per vagina. Leucorrhoea or blood stained discharge was the complaint of $40 \%, 50 \%$ had low backache, $10 \%$ decubitus ulcer was noted on examination. No patients complained of stress urinary incontinence. (Table 1) Patients with decubitus ulcer and UTI were treated appropriately before taking them up for surgery.

Uterocervical Length (UCL) in majority of patients, i.e. $47.5 \%$ was 3 inches, $20 \%$ had UCL of 3.5 inches, $10 \%$ had UCL of either 4 or 5 inches while $12.5 \%$ had 4.5 inches UCL.

Majority of the patients (62.5\%) had Grade 3 descent at the time of surgery. All sling operations were done for Grade III descents. Only two patients had Grade I descent and for them Shirodkar's uterosacral advancement was done (Table 2).

Purandare's abdominal cervicopexy (2 with; 6 without repair) and Shirodkar's uterosacral advancement (4 with; 2 without repair) was needed. Maximum, i.e. twelve patients i.e. $30 \%$ (9 with; 3 without repair) underwent Shirodkar's sling surgery, five patients i.e. $12.5 \%$ ( 4 with; 1 without repair) underwent Nadkarni's sleeve operation, four patients i.e. $10 \%$ underwent Fothergill's operation with repair and four patients i.e. $10 \%$ (4 with repair) underwent laparoscopic assisted cervicopexy.

Two patients developed spinal headache, one patient had secondary haemorrhage on the same day of surgeryShirodkar's uterosacral advancement. Re-suturing after vaginal exploration was done.

Out of 40 patients operated, nine patients wanted conception. Followup revealed out of them four patients i.e. (10\%) conceived. Three patients delivered normally at term. One patient had emergency LSCS in view of cephalopelvic disproportion. None of the patients aborted. In none of the patients, the prolapse recurrence was noted (Table 3).

\begin{tabular}{|c|c|c|}
\hline $\begin{array}{c}\text { Sl. } \\
\text { No. }\end{array}$ & Symptoms and Signs & No. (\%) \\
\hline 1 & Something coming out per-vagina & $40(100 \%)$ \\
\hline 2 & Leucorrhoea/blood stained discharge & $12(30 \%)$ \\
\hline 3 & Backache & $20(50 \%)$ \\
\hline 4 & Menstrual irregularities & $04(10 \%)$ \\
\hline 5 & $\begin{array}{c}\text { Chronic straining factors e.g. constipation, } \\
\text { coughing/heavy weight lifting }\end{array}$ & $11(27.5 \%)$ \\
\hline 6 & $\begin{array}{c}\text { Urinary symptoms: increased frequency/ } \\
\text { burning }\end{array}$ & $03(7.5 \%)$ \\
\hline 7 & Eager to conceive & $09(22.5 \%)$ \\
\hline 8 & Decubitus ulcer & $04(10 \%)$ \\
\hline
\end{tabular}

Table 1. Symptoms and Signs of Patients Studied $(n=30)$ 


\begin{tabular}{|c|c|c|c|c|}
\hline Types of & \multicolumn{3}{|c|}{ Degree of Prolapse } & \multirow{2}{*}{ Total } \\
\cline { 2 - 5 } Operation & I & II & III & \\
\hline $\begin{array}{c}\text { Purandare's } \\
\text { Cervicopexy }\end{array}$ & - & 3 & 5 & 8 \\
\hline $\begin{array}{c}\text { Shirodkar's } \\
\text { uterosacral } \\
\text { advancement }\end{array}$ & 2 & 3 & 1 & 6 \\
\hline $\begin{array}{c}\text { Shirodkar's sling } \\
\text { surgery }\end{array}$ & - & - & 12 & 12 \\
\hline
\end{tabular}

\begin{tabular}{|c|c|c|c|c|}
\hline $\begin{array}{c}\text { Nadkarni's sleeve } \\
\text { operation }\end{array}$ & - & 1 & 5 & 6 \\
\hline Fothergill's surgery & - & 1 & 3 & 4 \\
\hline $\begin{array}{c}\text { Laparoscopy } \\
\text { assisted cervicopexy }\end{array}$ & - & - & 4 & 4 \\
\hline Total (\%) & $\begin{array}{c}\mathbf{2} \\
\mathbf{( 5 \% )}\end{array}$ & $\begin{array}{c}\mathbf{1 3} \\
\mathbf{( 3 2 . 5 \% )}\end{array}$ & $\begin{array}{c}\mathbf{2 5} \\
(\mathbf{6 2 . 5 \% )}\end{array}$ & $\begin{array}{c}\mathbf{4 0} \\
\mathbf{( 1 0 0 \% )}\end{array}$ \\
\hline $\begin{array}{r}\text { Table 2. Type of Operation Performed } \\
\text { and Degree of Prolapse (n= 30) }\end{array}$ \\
\hline
\end{tabular}

\begin{tabular}{|c|c|c|c|c|c|c|}
\hline Types of Surgery & $\begin{array}{c}\text { No. of } \\
\text { Patients } \\
\text { Sterilised }\end{array}$ & $\begin{array}{c}\text { No. of } \\
\text { Patients } \\
\text { Follow-Up }\end{array}$ & $\begin{array}{l}\text { No. of Patients } \\
\text { Wanting } \\
\text { Contraception }\end{array}$ & $\begin{array}{c}\text { No. of } \\
\text { Patients } \\
\text { Conceived }\end{array}$ & Delivered & $\begin{array}{l}\text { Recurrence } \\
\text { of Prolapse }\end{array}$ \\
\hline Purandare's cervicopexy $(n=8)$ & 6 & 4 & - & - & - & - \\
\hline Shirodkar's uterosacral $(n=6)$ & 5 & 6 & 1 & - & - & - \\
\hline Shirodkar's sling surgery $(n=12)$ & 10 & 12 & 2 & 1 & 1 (FTND) & - \\
\hline Nadkarni's sleeve excision $(n=6)$ & 1 & 6 & 3 & 2 & $\begin{array}{l}1 \text { (FTND) } \\
1 \text { (LSCS) }\end{array}$ & - \\
\hline Fothergill's surgery $(n=4)$ & 2 & 4 & 1 & - & - & - \\
\hline $\begin{array}{l}\text { Laparoscopy assisted cervicopexy } \\
\qquad(\mathrm{n}=4)\end{array}$ & 2 & 4 & 2 & 1 & 1 (FTND) & - \\
\hline Total $(n=40)$ & 26 & 36 & 9 & 4 & $\begin{array}{l}3 \text { (FTND) } \\
1 \text { (LSCS) }\end{array}$ & - \\
\hline Percentage & $65 \%$ & $90 \%$ & $22.5 \%$ & $10 \%$ & & - \\
\hline
\end{tabular}

\section{DISCUSSION}

Uterovaginal prolapse is going to be a common malady in the Indian women and the best reconstructive surgery for the women in child bearing age group is going to be a dogma for many obstetricians and gynaecologists. ${ }^{[9]}$ Pregnancy itself results in a reduction of total collagen content, which may result in weakening of pelvic floor continence mechanisms.[10] Reconstructive operations are those, which aim at reconstruction of damaged support.

If women are under 35 years of age, her menstrual, sexual and reproductive function has to be conserved and some type of reconstructive surgery has to be done. In our study $80 \%$ patients were below 30 years of age, which is a period of maximum fertility. Hence, age is one of the most important factors in deciding the type of operation for uterovaginal prolapse. Parity and length of cervix had specific operation indication.

As shown in Table 2, 62.5\% patient had third degree descent. In this series, majority of patients i.e. $30 \%$ underwent Shirodkar's sling surgery. While all patients who underwent Shirodkar's sling surgery had third degree descent. Though technically difficult procedure, it is physiological and gives excellent end results.

Out of twelve patients with Shirodkar's sling operation, ten were sterilised and only 2 patients were interested in child bearing. Out of the two patients- one patient conceived and delivered normally at term. Hence, conception rate was $50 \%$ and success rate of surgery was $100 \%$ in Shirodkar's sling operation (Table 3).

In a study conducted by Dastur et al[11] reported anterior Shirodkar's sling surgery found unsuitable in childbearing age group, as it prevents dilatation of cervix in labour and necessitates a caesarean section while recurrence in only one patient.
In another study done by Suchitra Pandit et al[9] 46.67\% were in childbearing and underwent Shirodkar's sling surgery, while $41.37 \%$ conceived giving a good fertility rate.

Nadkarni's sleeve excision in six patients $(15 \%)$ in our study had complete follow-up. One patient was sterilised. Three out of five were interested in childbearing. Two patients conceived. Amongst them, one patient delivered normally at term and one patient underwent LSCS in view of cephalopelvic disproportion (Table 3).

In none of the patients prolapse recurred. Hence, conception rate in our series was $60 \%$, the recurrence was nil and success rate was $100 \%$. Hence, the sleeve excision has given excellent anatomical and obstetric results in our study.

In study Nadkarni's[12] found nine patients conceived, out of them four had full-term normal deliveries, four delivered by LSCS and one patient had a second trimester abortion.

Gautama N. Allahabdia[13] found all cases were either admitted in active labour or as cases of abortions or were treated for infertility. The incidence of FTND in his study was $66.6 \%$ and the incidence of caesarean section was 8.3. The recurrence rate of prolapse in their series was only $7.7 \%$.

Six patients underwent Purandare's cervicopexy, were sterilised and prolapse recurred in none. (Table 3) In a paper published by Ambiye et al, $77.4 \%$ delivered normally and $20 \%$ of the patients presented with infertility. While another study carried out by Purandare V.N., he reported that this operation had no effect on their fertility. Chaudhari S.K. et al[14] found conception rate of $66.67 \%$ and recurrence was seen only in one patient $(2.17 \%)$.

Following Shirodkar's uterosacral advancement in six patients (20\%), five patients were sterilised. Only one patient was interested in childbearing and was yet to conceive. There was no recurrence in any of the patient. Hence, the success rate of our Shirodkar's uterosacral advancement surgery was $100 \%$ (Table 3).

Ambiye et al reported $72.5 \%$ had normal delivery, $10 \%$ had LSCS. In $17.5 \%$ had dystocia due to failure to take up 
anterior lip of cervix. In another study conducted by Chaudhari S.K. et al,[15] fertility was not affected in these patients.

In our study, four patients underwent Fothergill's operation. In all of the patients, it was combined with AP repair. Two out of them were sterilised. One patient wanted conception, but did not conceive yet. Recurrence rate in our series was nil (Table 3).

Pritchard et al,[16] in his study stated that Fothergill's surgery leads to cervical incompetence, infertility, dystocia and increased operative delivery.

Jeffioate reported $75 \%$ to $90 \%$ patients failed to conceive after Fothergill's surgery; $20 \%$ to $50 \%$ patients had abortion and preterm labour due to incompetent os. There was increase in incidence of cervical dystocia leading to obstructed labour, which in turn increased the rate of LSCS. Precipitate labour was also seen due to loss of resistance of cervix. Traumatic and intrapartum and post-partum haemorrhage was also seen.

In this study the patients who underwent laparoscopicassisted cervicopexy were interested in further child bearing, had conception rate of $25 \%$. There was no recurrence in any of them (Table 3 ).

\section{CONCLUSION}

It can be concluded that different procedures in conservative surgeries of uterovaginal prolapse have their own advantages and disadvantages. Patient with prolapse are not approached with fixed plans. Each case is a separate one and should be treated accordingly. Each surgeon has his own preferences, but each operation should be properly indicated. Preventive measure is best management. Hence, with the programs implemented by the Government of India in the 5 years plan with stress to improve the literacy and awareness along with shorter confinements, partogram, augmentation of labour and small family norms, antenatal and postnatal exercises described by Koegel and Mandelstorm to reduce the incidence of prolapse.

\section{REFERENCES}

[1] Jelovsek JE, Maher C, Barber MD. Pelvic organ prolapse. Lancet 2007;369 (9566):1027-38.

[2] Te Linde RW, Rock JA. Te Linde's Operative Gynaecology. 9th edn. Lippincott Williams and Wilkins 2003:928.

[3] DeLancey JO. Anatomy and biomechanics of genital prolapse. Clinical Obstet and Gynaec 1993;36(4):897909.
[4] Thakar R, Stanton S. Management of genital prolapse. BMJ 2002;324(7348):1258-62.

[5] Mant J, Painter R, Vessey M. Epidemiology of genital prolapse. Observations from the Oxford family planning association study. Br J Obstetric Gynaecol 1997;104(5):579-85.

[6] Allard P, Rochette L. The descriptive epidemiology of hysterectomy, Province of Quebec, 1981-1988. Ann Epidemiol 1991;1(6):541-9.

[7] Beck RP. Pelvic relaxation prolapse. In: Case NG, Weingold AB. eds. Principles and practice of clinical gynaecology. New York: John Wiley 1983:677-85.

[8] Bump RC, Mattiasson A, Bo K, et al. Standardization of terminology of female pelvic organ prolapse and pelvic floor dysfunction. Am J Obstet Gynecol 1996;175(1):10-17.

[9] Pandit SN, Ghodake VB, Pawar VC. Evaluation of Shirodkar's sling surgery for conservative management of uterovaginal descent during child bearing age group. Bhj.org 2007.

[10] Granstorm L, Ekman G, Ulmsten U, et al. Proteoglycan metabolism in the connective tissue of corpus and cervix uteri during ripening and term labour in term pregnancy. $\mathrm{Br} \mathrm{J}$ Obstet and Gynaecol 1989;96(10):1198-202.

[11] Dastur B, Gurubaxani G, Palnitkar SS. Shirodkar's sling operation in the treatment of genital prolapse. Journal of Obst and Gynaec (British Commonwealth) 1967;74(1):125-8.

[12] Nadkarni RM. Supravaginal elongation of cervix in uterine prolapse. Paper read at the $19^{\text {th }}$ Annual conference of the Mumbai. Obstetrics and Gynaecology Society 1986.

[13] Allahabdia GN. Reproductive performance following sleeve encision anastomosis operation for genital prolapse. The Australian and New Zealand Journal of Obstetrics and Gynaecology 1992;32(2):145-53.

[14] Chaudhari SK. Operative treatment of genital prolapse in young women. Journal of Indian Medical Association 1983,80:167-72.

[15] Chaudhari S.K The place of sling operation in treating genital prolapse in young women. International Journal of Obstetrics and Gynaecology 1979;16(4): 314-20.

[16] Pritchard J, Macdonald P, Gant N. William Obstetrics. 19th edn. Appleton 1993. 